\title{
AVALIAÇÃO NA EDUCAÇÃO SUPERIOR: LIMITES E POSSIBILIDADES DE UMA EXPERIÊNCIA
}

\section{EVALUATION IN HIGHER EDUCATION: LIMITS AND POSSIBILITIES OF AN EXPERIENCE}

\author{
Marcos Villela Pereira \\ Doutor em Educação (PUCSP) \\ Professor Titular da Pontifícia Universidade Católica do Rio Grande do Sul (PUCRS) \\ marcos.villela@pucrs.br \\ Sônia Maria de Souza Bonelli \\ Doutor em Educação (UFRGS) \\ Professor Adjunta da Pontifícia Universidade Católica do Rio Grande do Sul (PUCRS) \\ sbonelli@pucrs.br \\ Rosane Oliveira Duarte Zimmer \\ Doutora em Educação (PUCRS) \\ Professora da Pontifícia Universidade Católica do Rio Grande do Sul (PUCRS) \\ rosane.zimmer@pucrs.br \\ Síntia Lúcia Faé Ebert \\ Doutora em Educação (PUCRS) \\ Professora da Pontifícia Universidade Católica do Rio Grande do Sul (PUCRS) \\ http://lattes.cnpq.br/9996198887485025 \\ sintia.ebert@pucrs.br
}

Resumo: O artigo coloca em análise a concepção de avaliação praticada por um grupo de professores supervisores de Estágio Curricular de um curso de Pedagogia, nos anos iniciais do Ensino Fundamental, com base na ideia de que a avaliação propicia ao professor uma reflexão sobre sua prática, para que, a partir da tomada de consciência sobre suas convicções, possa empregar estratégias de ação, desenvolver instrumentos e rever aspectos que precisem ser retomados, na busca do enfrentamento das dificuldades encontradas ao longo da jornada educativa. Para os estudantes, a avaliação pode ser reconhecida como o momento de construção do conhecimento e reposicionamento do processo de formação. A avaliação é entendida como um ato político, no sentido de fornecer sucessivos juízos sobre um percurso, sempre parciais, provisórios e precários, que instam os sujeitos a ajustar o curso dos acontecimentos às suscetibilidades do próprio grupo, no interior de um dado contexto de ação pedagógica ou formação social. Por fim trazemos alguns registros do percurso de realização do Estágio Curricular, nos anos iniciais, no qual fomos interpelados pela pandemia de COVID-19 e experimentamos o e-portfólio como dispositivo de apropriação crítica e de avaliação formativa, permitindo uma experiência de deslocamento e consequente ampliação de nosso entendimento sobre as possibilidades do vínculo na educação remota, em tempos de exceção.

Palavras-chave: Avaliação. Educação superior. Estágio curricular nos anos iniciais. Portfólio. Pandemia de COVID-19.

\begin{abstract}
This paper analyzes the conception of evaluation practiced by a group of supervisors of the Curricular Internship in the early years in a Pedagogy undergraduation program, starting from the idea that evaluation provides the teacher with a reflection on his practice so that, from the awareness of their convictions, can employ action strategies, develop tools and review aspects that need to be taken up, in the search for facing difficulties encountered along the educational journey. For students, evaluation can be recognized as the moment of knowledge construction and repositioning of the training process. The evaluation is understood as a political act, in the sense of providing successive judgments on a path, always partial, provisional and precarious, that urge the subjects to adjust the course of events to the susceptibilities of the group itself, within a given context of action pedagogical or social formation. Finally, we bring some records of the course of the curricular internship in the early years, in which we were challenged by the COVID-19 pandemic and tried the e-portfolio as a device for critical appropriation and formative evaluation, allowing an experience of displacement and consequent expansion of our understanding of the possibilities of bonding in remote education, in times of exception.
\end{abstract}

Keywords: Evaluation. High education. Curricular internship in the early years. Portfolio. COVID-19 pandemic.

\section{Para citar - (ABNT NBR 6023:2018)}

PEREIRA, Marcos Villela; BONELLI, Sônia Maria de Souza; ZIMMER, Rosane Oliveira Duarte, EBERT, Síntia Lúcia Faé. Avaliação na educação superior: limites e possibilidades de uma experiência. Eccos - Revista Cientifica, São Paulo, n. 55, p. 1-21, e18874, out./dez. 2020. Disponível em: https://doi.org/10.5585/eccos.n55.18874. 


\section{Situando a questão}

É sempre um desafio falar em avaliação. Esse é um assunto impossível de ser encerrado, uma vez que o modo como produzimos, organizamos e vivemos nas diferentes formações sociais que fazem adjacência com a escola e suas tipologias exige que pratiquemos expedientes avaliativos de forma constante, sistemática e permanente.

A educação, na forma escolar, atende a uma iniciativa civilizatória inaugurada com a modernidade. Seu propósito mais fundamental é sistematizar o governo das condutas dos indivíduos, em sua preparação para a vida em sociedade. Kant (1996) já nos dizia que o principal objetivo da escola é ensinar os alunos a obedecer e a controlar seus corpos; toda a instrução, baseada nos conteúdos das então nascentes disciplinas escolares, bem como a chamada educação prática (a aprendizagem dos valores e princípios de sociabilidade) vêm em sequência.

Com o tempo, a sofisticação das estratégias pedagógicas conduziu o arranjo desses dispositivos para uma imbricada interimplicação, de modo que os processos de desenvolvimento cognitivo produzem efeitos diretos sobre a condução das condutas - ao desenvolver as habilidades de formalização do pensamento necessárias à aprendizagem nos moldes da racionalidade dominante, o sujeito desenvolve estratégias de construção da realidade. Ao desenvolver os expedientes de classificar, ordenar e seriar, por exemplo, necessários à atividade relativa à lógica formal, o sujeito é treinado para estabelecer e reconhecer relações hierárquicas, compreender a importância das sequências ordenadas e conduzir sua existência sob os princípios da lógica clássica - princípio da identidade, do terceiro excluído e da não contradição.

Entendida desse modo, compreende-se a escola como um dos principais dispositivos civilizatórios e mantenedores da forma de racionalidade que será hegemônica até hoje. Essa operação toda, para funcionar de acordo com a expectativa daquela abstração que é a construção de um certo estado de bem-estar social, ancora-se sobre os expedientes da disciplina e do controle, dispositivos que funcionam com o intuito de regular e governar a conduta de homens e instituições. Baseada na polarização do juízo, estabelecido entre os extremos do bem e mal, bom e mau, verdadeiro e falso, certo e errado, a avaliação objetiva escrutina uma certa prática (a resposta a uma questão, a resolução de um problema, o desenvolvimento de uma habilidade, uma mudança de atitude, um procedimento, uma proposição etc.) e, a partir da comparação com um parâmetro definido em função dos objetivos pretendidos, classificar o sujeito de acordo com o grau de coincidência ou correspondência entre a proposição e o critério. 
Vale destacar que esse expediente, que estabelece um parâmetro ou critério, pretende objetivar uma construção subjetiva, ou seja, um sujeito (individual ou coletivo) delineia um objetivo a ser alcançado (um estado para a realidade, um projeto, um propósito) a partir das suas próprias expectativas. Esse objetivo, arranjado no interior de uma dada formação social, toma forma na medida em que a ele são associados discursos instituintes que, por sua vez, servirão de parâmetro para a associação de outros sujeitos, com vistas à sua legitimação. Esse objetivo, então legitimado e tornado hegemônico, adquire um status de objetividade, ou seja, passa a ser tomado como um estado desejável e, nessa medida, deverá servir de parâmetro para julgamento das atitudes, proposições e práticas dos demais indivíduos. Ao fim e ao cabo, é um construto subjetivo que, por efeito de um arranjo político que constitui uma dada formação social, é alçado a um status de objetividade que passa a regular o conjunto social sobre o qual se estende.

Nesse sentido, podemos considerar que os parâmetros e critérios são sempre relativos, uma vez que, de um lado, são oriundos de uma certa configuração subjetiva, particular, localizada no tempo e no espaço e, por outro lado, dizem respeito a uma determinada circunstância, uma também particularidade. Entretanto, ainda que os consideremos relativos, em função da necessidade de aplicá-los, em sua operação eles adquirem um valor absoluto. O que queremos dizer é que a relatividade de parâmetros e critérios só existe enquanto eles não são aplicados, enquanto eles são mera possibilidade. Nesse estado, dada a plausibilidade de operação de outros critérios e parâmetros, por sua vez afeitos e, portanto, relativos a outras particularidades, há um sem número de possibilidades de formular-se critérios e parâmetros, todos eles razoáveis, de acordo com as circunstâncias de quem os formula e a que se aplicam e com que objetivos. No momento em que entram em operação, quando são aplicados, fundamentam um julgamento, servem de estofo e argumento para proferir-se um juízo e, nesse momento, tiram de cena todo aquele leque de possibilidades (que permanecem apenas como possibilidade não sida), em favor da emergência de um padrão que, naquela circunstância, opera como um valor absoluto.

Ainda que se possa considerar um procedimento corriqueiro, a avaliação resulta em um expediente de alta complexidade e relevância para refletir, analisar e (re)definir os rumos do processo de formação coletivo e individual. Mais do que afirmar que a avaliação pode ser uma faca de dois gumes ou uma moeda com dois lados, somos levados a dizer que ela tem muitos aspectos, funções e perspectivas de alcance, dificilmente apreensíveis em modelos mais simples. Neste trabalho, vamos procurar nos ater às dimensões relativas ao escrutínio do processo formativo de sujeitos que ingressam em carreiras acadêmicas na Educação Superior, 
cujo escopo se dirige ora na direção da avaliação da aprendizagem de conteúdos e habilidades articuladas ao conjunto de saberes necessários ao ingresso em uma profissão, ora na direção da avaliação do desenvolvimento de competências aplicadas à performance subjetiva dos indivíduos em processos coletivos que vão da sala de aula ao campo de prática profissional, como no caso das aulas práticas e estágios. Ao colocar em análise algumas das nossas experiências avaliativas, entendemos que é o próprio fundamento da avaliação que colocamos em questão, e não apenas a particularidade de uma prática mais ou menos bem-sucedida.

\section{A particularidade da origem: avaliação na sala de aula}

Existe um expediente já tornado clássico que pondera a situação vivida por Alice no outro lado do espelho como metáfora para muitas práticas avaliativas: muitas vezes, o processo de avaliação replica a discronia da história, onde primeiro Alice é condenada, depois é julgada e só por fim ela comete o delito (CARROL, 2010). Essa comparação denuncia muitas práticas autoritárias, quando o professor, valendo-se de sua prerrogativa de gestor pedagógico, determina o destino e profere juízos sobre estudantes que ainda sequer entenderam a sua proposta.

Como já mencionamos, a avaliação sempre implica em juízo, em julgamento. E todo julgamento supõe parâmetros e critérios. Muitas vezes, os parâmetros permanecem ocultos para o próprio professor, que não tem clareza sobre as crenças e convicções sobre as quais baseia seus juízos. Outras vezes esses parâmetros são tomados como elementos objetivos, como se fossem inquestionáveis. Outras, ainda, respondem a demandas institucionais, atreladas a matrizes curriculares ou diretrizes similares. Como afirma Garcia (2009, p. 205):

[...] as práticas de avaliação da aprendizagem na educação superior recaem sobre um conjunto limitado de escolhas. Geralmente, tais estratégias se concentram no uso de procedimentos da "avaliação somativa", exercidos ao final de determinado período ou unidade de ensino. Isso implica, por exemplo, a manutenção de uma antiga e persistente cultura avaliativa que tende a destacar particularmente a utilização de provas escritas para avaliar o grau de aprendizagem dos alunos. [...] É interessante considerar que as formas predominantes de avaliação da aprendizagem na educação superior refletem não somente as escolhas pedagógicas exercidas pelos professores, mas também as diretrizes curriculares dos cursos universitários, ou, ainda, de modo mais amplo, a própria cultura institucional que os influencia.

Quando somos convocados a pensar na sala de aula, na aprendizagem e nas estratégias de avaliação, tomando em consideração a diversidade e a heterogeneidade dos grupos de estudantes, somos compelidos a romper os limites desse tipo de determinação. Mais do que centrar a avaliação em expedientes de mensuração da aprendizagem objetiva, trata-se de ampliar esse entendimento e incluir, por exemplo, a possibilidade de utilização dos conteúdos 
trabalhados para interferir na realidade - seja na resolução de problemas ou na construção de projetos, seja na leitura e interpretação da realidade. Se os conteúdos são ferramentas para o entendimento e a compreensão da realidade do mundo, somente terão sentido na medida em que estiverem em operação, em adjacência com contextos e conjunturas particulares. Nesse sentido, a avaliação tem profundas implicações do modo como acolhemos e lidamos com a diversidade na sala de aula: a singularidade de cada sujeito e grupo se traduz em leituras singulares do mundo e, portanto, em singulares modos de agir. Para além da avaliação baseada no desenvolvimento cognitivo e na aprendizagem objetiva, estamos postulando a necessidade de praticar-se uma avaliação que dê conta de produzir leituras coletivas e momentâneas de percursos e processos vividos por professor e alunos no contexto da sala de aula.

A avaliação assim entendida é, definitivamente, um ato político, no sentido de fornecer sucessivos instantâneos sobre um percurso, sempre provisórios e precários, que instam os sujeitos a ajustar o curso dos acontecimentos às suscetibilidades do próprio grupo, no interior de uma dada formação social. Trata-se de um instantâneo precário porque sempre será resultado de uma visão particular, de um sujeito ou de um grupo, posicionado historicamente e com seus interesses e particularidades. Um ponto de vista produz uma perspectiva, e a soma das perspectivas nunca alcança a totalidade de possibilidades de entendimento e leitura. Por isso é sempre precário. E é provisório porque o grupo está vivo, no interior de uma formação social e, portanto, suscetível a toda sorte de interferências. Novas leituras de mundo podem suscitar novos projetos, novos conhecimentos podem suscitar novos juízos, e assim por diante. Dessa maneira, o resultado de uma avaliação não será tomado como um veredito definitivo acerca de um objeto, mas um retrato momentâneo daquele estado de coisas, sempre passível de ser modificado tão logo a realidade sofra alguma interferência.

Vejamos, a seguir, alguns aspectos que contribuem para que coloquemos em pauta o incremento da diversidade de sujeitos na sala de aula.

\section{A diversidade no campo de prática: democratização do acesso à educação superior}

O Plano Nacional de Educação (PNE 2014-2024) foi aprovado pela Lei n. ${ }^{\circ} 13.005$ no dia 25 de junho de 2014 (BRASIL, 2014), pela então Presidente da República, Dilma Rousseff. O PNE 2014-2024 estabelece 20 metas e estratégias que deveriam determinar diretrizes para a política educacional dos dez anos compreendidos no intervalo. Em relação ao acesso, a meta 12 postula a elevação da "taxa de matrícula na educação superior para $50 \%$ e a taxa líquida para 
$33 \%$ da população de 18 a 24 anos" assegurando a "qualidade da oferta e expansão para, pelo menos, $40 \%$ (quarenta por cento) das novas matrículas, no segmento público” (BRASIL, 2014).

Apesar de um aumento significativo de matrículas na educação superior, a universidade ainda está longe de tornar-se acessível às camadas periféricas ao estrato dominante. O simples acesso não é suficiente para que se caracterize a democratização da educação superior, é necessário que se assegure a permanência do estudante e, se pensarmos dessa maneira, precisamos considerar a necessidade de:

[...] uma formação resultante de aprendizagem efetiva, relevante e pertinente. A reestruturação do fazer acadêmico articulando descentralização administração e integração institucional. A interação efetiva com os diversos segmentos da sociedade. A construção de pontes para o futuro revendo os paradigmas que norteiam as atividades acadêmicas, tanto no processo de formação envolvendo currículo, ensinoaprendizagem, avaliação, como na articulação da graduação com a pós-graduação, na produção e disseminação do conhecimento e na gestão. (ZAINKO, 2003, p. 55-56).

Considerando os dados do INEP, observa-se que em 2017 existiam 35.380 cursos de graduação, nas modalidades Bacharelado, Licenciatura ou Tecnólogo. Nesse universo, encontramos 8.451 .748 matrículas realizadas, representando um aumento de 44,6\% se ponderarmos o interstício entre 2008 e 2018 (INEP, 2019).

Visando à ampliação esse percentual, ainda em 2017 o MEC editou o Decreto no 9.057, que define novas regras para a Educação a Distância, possibilitando que as IES ampliassem a oferta de cursos de graduação (e pós-graduação lato sensu) a Distância. O Decreto permite tanto a criação de polos pelas próprias IES como o credenciamento das IES para essa modalidade, sem a oferta simultânea do curso na modalidade presencial. Mesmo com essas possibilidades, a elevação do número de jovens matriculados na educação superior brasileira chega a apenas 20\% em 2018 (INEP, 2019): se considerarmos como universo potencial o número de jovens com idades entre 18 e 24 anos (encontramos 23.870.718, em 2018) (INEP, 2019), sugerindo uma conta aproximada de 15 milhões de jovens com idade compatível fora da Educação Superior.

De toda sorte, mesmo tendo como panorama essa situação pontual e sem dados posteriores, observamos que o crescimento de 44,6\% havido naquele interstício de dez anos é bem significativo - especialmente se considerarmos que junto com o crescimento numérico vem junto a diversidade de sujeitos ingressantes na Educação Superior. Esse aumento de matrículas representa um efeito de diferentes políticas: aumento no número de vagas, política de cotas, financiamento estudantil e programas como REUNI (Programa de Apoio a Planos de Reestruturação e Expansão das Universidades Federais) e PROUNI (Programa Universidade para Todos), dentre outros, efetivando o ingresso de estudantes com características e 
singularidades que vão impulsionar definitivamente a Educação Superior à exploração de novas formas de ensinar e avaliar.

\section{Diferentes sujeitos, diferentes modos de aprender, de ensinar e de avaliar}

Com esse olhar, reposicionamos o desafio inicial: como desenvolver uma boa educação levando em consideração o potencial de cada aluno, sabendo que cada pessoa é única e irrepetível? E, na esteira dessa condição, como avaliar? Cabe ao professor, ao conhecer minimamente a diversidade de suas turmas para poder experimentar alternativas de ensino na construção do planejamento, na condução das atividades de aprendizagem e nas práticas de avaliação.

Nessas últimas décadas temos presenciado uma transformação dos contextos da Educação Superior ante a necessidade de dar respostas à diversidade existente e suas implicações no domínio e capacitação para o uso de dispositivos e ferramentas pedagógicas. Podemos acompanhar algumas ponderações de Benítez, Aguilar e Sánchez (2019), que apontam um extenso conjunto de características presentes nas aulas: as aulas tendem a deixar de ser reativas, deixando de ter um enfoque único para todo o grupo, e um arranjo pautado na diversidade de fontes e materiais de referência; articulam as atividades e tarefas à realidade cotidiana, abrindo-se para diferentes modos de acontecimento; o conhecimento está em permanente construção, apesar da necessidade de domínio do conhecimento consolidado historicamente; a aprendizagem deve ser significativa e orientar o planejamento, demandando a experimentação de diferentes situações e estratégias de ensino. Propondo a diversificação da aula universitária, as mesmas autoras (BENÍTEZ; AGUILAR e SÁNCHEZ, 2019) também indicam algumas sugestões: que os conteúdos sejam selecionados e ordenados em função da sua relevância para a formação e prática profissional futura dos estudantes; que a diversidade e as diferenças entre os estudantes sejam tomadas como indicativo de diferentes modos de ver o mundo e solucionar problemas; que a avaliação seja permanente e continuada, de maneira que o processo sofra interferências tanto por parte do professor quanto dos estudantes; que as práticas e experiências colaborativas (alunos-professor e alunos-alunos) sejam prioridade no planejamento e no desenvolvimento das disciplinas; que o processo seja diversificado de acordo com as necessidades e demandas do grupo, não apenas como uma estratégia vazia.

As implicações sobre a avaliação, nesse caso, se fazem sentir de forma imediata. Além de avaliar o produto (da aprendizagem, da aula, da unidade), todo o percurso precisa ser considerado. As eventuais divergências de compreensão que emergem na sala de aula indicam 
diferentes hipóteses de compreensão da situação dada, bem como revelam diferentes alternativas de enfrentamento. Nesse caso, ao invés de buscar-se uma verdade, uma resposta correta, obtemos uma variedade de entendimentos e compreensões que poderão ser exploradas de forma coletiva na própria rotina da sala de aula.

A avaliação permanente possibilita que sejam retomados os objetivos e propósitos da aula e suas formas de entendimento e apropriação por parte dos estudantes. Entendemos que mais do que um contrato didático, o que se estabelece entre professor e turma é um pacto ou um compromisso coletivo. Trata-se de um combinado entre as partes que deverá orientar as rotinas e a atitude esperada de cada um e pelos outros: em que ponto estamos, onde queremos chegar, por onde vamos andar, que caminhos vamos percorrer, que construções precisamos fazer. A diferença da estratégia clássica é que essa combinação é afetada pelo contexto e pela conjuntura, ou seja, ao longo do percurso outros propósitos podem aparecer, outros desafios podem surgir, assim como se pode observar que um expediente não está funcionando como se desejava, e assim por diante. Nesse caso, durante o processo são levantados indicadores e sinais acerca do percurso de maneira que o pacto ou compromisso entre professor e turma seja reeditado sistematicamente. Ou seja, mais do que centrar a avaliação na tarefa do diagnóstico, trata-se de pensar a avaliação como um conjunto de ponderações, análises e reflexões que permitam a sucessiva tomada de decisão no cotidiano da aula.

Essas alterações, por sua vez, também fazem ampliar outras noções implicadas no processo pedagógico. Por exemplo, abre-se espaço para a emergência de outras inteligências e outras formas da racionalidade, para além do modelo formal tornado hegemônico pela escola moderna. É quase possível afirmar que há tantas formas de racionalidade quantos são os sujeitos no interior de um grupo, especialmente porque cada sujeito é capaz de experimentar diferentes abordagens, diferentes razões, diferentes inteligências, de forma combinada. Nesse caso, desaparece a centralidade de um modelo ou exemplo de excelência: os chamados standarts, entendidos como padrões ou parâmetros de qualidade dão lugar à diversidade e à diferença, permitindo que se valorize a singularidade de cada estudante, grupo, projeto ou proposta.

Obviamente, isso desloca a centralidade do professor. Aquela posição que ele costumava ocupar, na educação tradicional, é desfeita e transformada. É fato que ele continua tendo a prerrogativa da condução do processo como um todo, assim como a responsabilidade institucional de emitir os juízos avaliativos. A autoridade do docente não é desfeita, mas seu lugar é modificado. Ele precisa ampliar seu olhar e aumentar a superfície de contato com o grupo, prestando atenção na efervescência de características e diferenças que passarão a preencher o tempo da aula. E isso implica, evidentemente, em formação e condições de 
trabalho. Para pensar-se na operação da aula diversificada, precisamos oferecer mais tempo remunerado e melhores condições de trabalho ao docente, que terá multiplicadas as tarefas e atividades correlatas ao desenvolvimento da aula: domínio de ferramentas diversificadas, tempo de estudo e leitura, habilidade no manejo e resolução de conflitos, ampliação do repertório de referência são algumas das exigências mais simples que assomam em seu horizonte.

Por fim, destacamos a importância do trabalho em rede. Há pouco falamos da importância do trabalho colaborativo, assim como há alguns anos defendia-se o trabalho interdisciplinar: o que destacamos é a importância da abertura para conexões e articulações entre campos de conhecimento e sujeitos neles atuantes, sejam professores, sejam outros profissionais, sejam os praticantes, sejam os usuários ou destinatários dos produtos e processos sobre os quais trabalhamos. Assegurando-se aquela prerrogativa a que nos referíamos acima, o professor tem a possibilidade de estabelecer redes de trabalho, de estudo e de experiência, articulando esses diferentes sujeitos, com suas singularidades, de modo a tornar a aula um ambiente efetivamente diversificado. Ao considerar e valorizar diferentes naturezas de saber, a aula se abre para a realidade diversa do mundo e a avaliação deixa de buscar um juízo definitivo e absoluto que se paute pelo verdadeiro ou falso, pelo certo ou errado. Cada situação nova e cada grupo novo demandam um novo entendimento e um novo encaminhamento. Por mais que seja necessário o estabelecimento do valor temporário para um juízo (as coisas precisam valer como verdadeiras ou corretas durante um tempo, de modo a viabilizar a execução de um plano ou projeto), quando o trabalho é feito em rede e/ou de forma colaborativa todos estão implicados e, portanto, todas as transformações da realidade produzem implicações no processo e, assim, demandam avaliação e autoavaliação constantes.

\section{Avaliação formativa na educação superior}

A avaliação formativa tem se tornado um instrumento essencial no atual momento da pandemia de COVID-19, que assola o planeta e compromete absolutamente todos os expedientes rotineiros. A avaliação, por muitos anos discutida pelos mais diversos autores sejam eles europeus (SACRISTÁN e GOMEZ, 1998; GRÉGOIRE, 2000; ZABALZA, 2013), norte-americanos (BARKLEY e MAJOR, 2020) ou brasileiros (HOFFMANN, 2013; LUCKESI, 2018; VASCONCELLOS, 2013; SILVA, 2019; GRILLO e GESSINGER, 2010; GIL, 2008) - parece que encontra, na situação atual, um lugar de destaque, uma vez que todos nos perguntamos: e agora? Como avaliar? Como fazer prova? Que instrumentos utilizar? É 
preciso olhar para a avaliação formativa e sua importância no processo de aprendizagem de nossos alunos.

Já em 2006, Carvalho e Gil-Pérez (2006, p. 59) eram enfáticos ao afirmar que é necessário romper com a "rememoração repetitiva dos conhecimentos teóricos e sua aplicação igualmente repetitiva a exercícios com lápis e papel, [...] é preciso acompanhamento e feedback constante em relação às finalidades estabelecidas para o ensino". Assim, já defendiam a relevância de entender a avaliação como processo e diagnóstico. Para Luckesi (2017, p. 9), avaliar é "julgar dados relevantes para tomar uma decisão". Diante disso, para o autor, seria necessário, em um primeiro momento, adotar um posicionamento epistemológico explícito, que irá nortear a prática pedagógica. Um segundo ponto trata de cada um assumir esse posicionamento como parte de si mesmo, para transformar, efetivamente, a prática e um terceiro e fundamental aspecto envolve resgatar a avaliação como processo diagnóstico e formativo para uma tomada de decisão.

Conceber a avaliação, nesse sentido, significa utilizá-la não só aos finais de trabalho, mas continuamente, do início ao fim das atividades, com propostas que subsidiem uma ação para a realização da avaliação final. Esse resultado proporcionará ao professor uma informação de como estão os alunos, em relação a um determinado conteúdo, partindo, então, para a organização e seleção deste, aprofundando-o de acordo com a resposta da avaliação. Convém ressaltar que tanto a Lei de Diretrizes e Bases da Educação Nacional (BRASIL, 1996), como a Base Nacional Comum Curricular (BRASIL, 2019) corroboram esse posicionamento.

Se o professor acompanha todo o processo de crescimento e desenvolvimento da construção do conhecimento de seus alunos, ao final ele provavelmente terá possibilidade de saber o que o aluno aprendeu, passando os resultados da avaliação a serem concebidos como uma referência para a reorientação da prática educacional. Quanto aos critérios de avaliação, o razoável é que eles estejam vinculados aos objetivos e conteúdos propostos para cada etapa do desenvolvimento cognitivo, afetivo e social, uma vez que devem estar articulados às expectativas de aprendizagem.

A partir dos resultados das avaliações, é desejável tomar decisões que não devem estar ligadas somente à reorganização da prática, mas, também, a outras medidas, como o planejamento e a organização de grupos de estudos, atividades extraordinárias, leituras adicionais, conforme a necessidade de cada grupo.

A avaliação propicia ao professor uma reflexão sobre sua prática para que, a partir da tomada de consciência sobre suas convicções, possa empregar estratégias de ação, desenvolver instrumentos e rever aspectos que precisem ser retomados, na busca do enfrentamento das 
dificuldades encontradas ao longo da jornada educativa. Para os alunos, é o momento de "reconstrução" do processo de construção do conhecimento. Reconstrução no sentido de interiorização de sua trajetória, de estabelecer significado, a partir de conhecimentos e experiências anteriores.

Diante disso, parece-nos fundamental que as avaliações contemplem o que é significativo para os sujeitos envolvidos na ação pedagógica, o que é essencial em cada área de conhecimento e que tenham mais ou menos o mesmo grau de complexidade das atividades realizadas em aula, com questões que envolvam análise crítica e níveis mentais mais elaborados, reforçando a compreensão de fatos e conceitos, com critérios bem definidos para valorizar o que se quer, de acordo com a realidade dos educandos.

É comum ouvirmos dos professores que acreditam em uma avaliação processual e contínua que o que os impede de proceder desse modo é o tempo escasso e a quantidade de conteúdos que precisam ser "dados". O fato é que os alunos não seguem o mesmo tempo que os cronogramas, isto é, cada um ou cada grupo tem o seu ritmo de aprendizagem: alguns mais rápidos, outros nem tanto - o que não significa que não aprenderam ou que não aprenderão, apenas que possuem um tempo diferente. Logo, cabe a nós, professores, estabelecermos estratégias de manejo da aula de forma a considerar positivamente a heterogeneidade do grupo.

Dessa forma, torna-se indispensável rever a questão do tempo, a sua relação com a aprendizagem e, por consequência, com o processo avaliativo, buscando uma (re)organização do planejamento com experiências que tenham sido significativas, experimentando novos rumos metodológicos para levarmos adiante uma avaliação contínua (HOFFMANN, 2008).

Trazendo esse processo para a atualidade, Silva (2019) indica oito pressupostos para fazer uma avaliação formativa, os quais apresentamos no diagrama abaixo. 
Figura 1 - Pressupostos para uma avaliação formativa

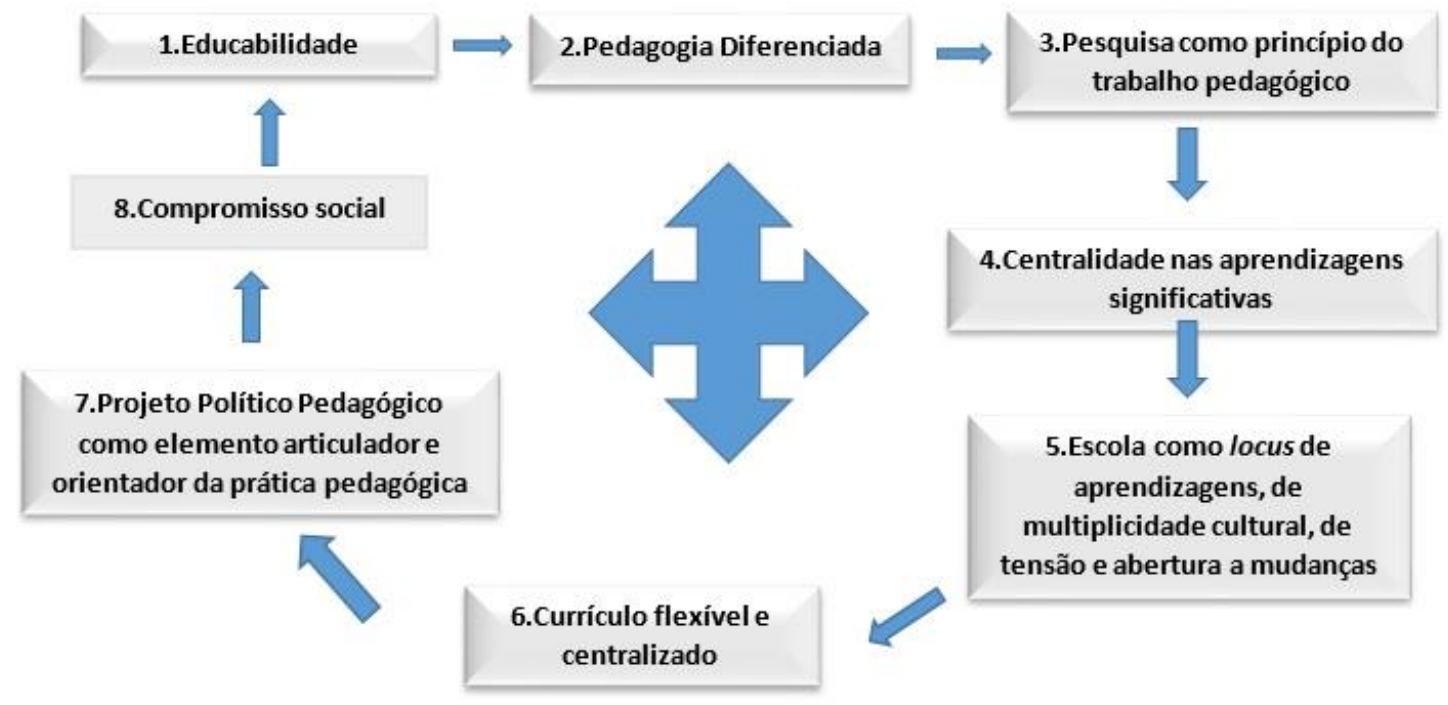

Fonte: Adaptado de SILVA (2019).

Como o próprio diagrama mostra, os princípios não são lineares, mas sim complementares; dessa forma, todos estão interligados e presumem a formação de um profissional reflexivo, que consiga compreender o processo avaliativo como práxis, articulando ação - reflexão - ação, na experiência de mudanças dentro da sociedade atual. Para Silva (2019), a avaliação formativa permite o acompanhamento do professor, em relação ao processo de ensino e aprendizagem dos alunos, o qual exige planejamento e intencionalidade para desenvolver situações didáticas desafiadoras e significativas - o que sempre é um desafio subjetivo, como já ponderamos nas seções iniciais deste artigo.

A avaliação, entendida dessa maneira, exige a definição de objetivos claros, articulados com um bom conhecimento de quem serão os sujeitos avaliados e a que ponto se pretende chegar. Em se tratando da Educação Superior e de algumas experiências práticas, podemos mencionar algumas atividades que podemos utilizar como ferramentas e instrumentos para experimentar a avaliação formativa. De acordo com Barkley e Major (2020), vale utilizar exercícios de conhecimento prévio, notas de leitura orientada, resumos e/ou resenhas, testes em grupo, comentários de citações, exercícios do tipo “Qual é o problema?”, revisão de problemas por pares, projetos digitais, mapas conceituais, diário sobre questões contemporâneas, produção de texto em duplas, artigo de síntese, livro da turma, discussão livre, diálogos dramáticos, narrativa digital, e-portfólio, ambiente de aprendizagem individual, entre outros.

Como podemos perceber a lista de possibilidades é imensa, e cada uma dessas atividades pode ser descrita e avaliada a partir dos objetivos do professor, bem como cada uma delas tem um propósito possível a partir do conteúdo desenvolvido dentro de uma categoria que pode ser 
de conhecimento fundamental, de aplicação, de integração, de dimensão humana, de interesse ou, até, de aprender a aprender, cabendo ao professor a preparação e condução da atividade a partir da explicitação dos seus propósitos na ação educativa. Ao final provavelmente seja possível identificar quais foram as aprendizagens dos estudantes e quais as dificuldades por eles encontradas e, assim, reorientar o trabalho.

\section{0 contexto da experiência}

Como já afirmamos, a avaliação é ponto recorrente em processos de ensinar e aprender, em relações estabelecidas que, prolongadas, expressam o projeto humano que se compreende em determinado tempo e espaço. Assumir uma avaliação que efetivamente contribua com o sujeito aprendente é um encaminhamento possível na intencionalidade curricular expressa no projeto político pedagógico de uma instituição educacional. E superar o binarismo aprovar/reprovar é um grande desafio quando esse projeto está baseado no ciclo humano de "aprendência".

Nesse sentido, a presente reflexão foi construída a partir das experiências em nosso cotidiano como professores, na especificidade de cursos de formação de professores. O trato com a avaliação é recorrente não apenas em nossa rotina de formadores, mas na constância de nosso percurso dialógico de pesquisar-ensinar-aprender-compartilhar a formação de professores para a Educação Básica.

Nossa instigação, em tempos antes e durante a situação da pandemia, é aludir em torno da avaliação a partir dos limites que hoje se apresentam - de modo especial, no que diz respeito às possibilidades de desequilíbrio daquele binarismo, produzindo um deslocamento na direção de ensinar e aprender pesquisando para, então, ampliar e qualificar o repertório de experiências acadêmicas.

Temos um exercício permanente de revisitar algumas práticas que consideramos anacrônicas para o projeto humano que se pretende, em curso de Pedagogia para este século. Entre elas, destacamos a prática de exames que, como observa Foucault (2006, p. 154): “combina com as técnicas da hierarquia que vigia e as da sanção que normaliza. [...] Estabelece sobre os indivíduos uma visibilidade através da qual são diferenciados e sancionados", deslocando o que aqui chamamos da 'examinação', para a prática de provas, a era da "provação". Conforme observamos acima, o manejo da avaliação é uma experiência geralmente incômoda, árdua e incerta. Por exemplo, a alegoria registrada por Perrenoud (1999, p. 9), da avaliação como um instrumento de tortura inventado tardiamente nos colégios do século XVII 
e consolidado e se tornado imprescindível para o ensino de massa desde o século XIX, nos parece ainda adequada.

A prática avaliativa, tanto pela "examinação" como pela "provação", funda-se na escolha de instrumentos para a mensuração da aprendizagem. Essa escolha tende a ofuscar o protagonismo do estudante e, ao mesmo tempo, reforça a prerrogativa do professor, uma vez que é ele quem seleciona e ordena o conteúdo e o modo como sua aprendizagem será avaliada, ele é quem determina quantas, quais e como as questões serão dispostas, como serão corrigidas, além da atribuição de níveis para classificação que devem resultar em juízos de aprovação ou reprovação no processo.

$\mathrm{Na}$ condição de acompanhar, orientar e supervisionar os percursos de estudantes do curso de Pedagogia no Estágio Curricular nos Anos Iniciais do Ensino Fundamental em nossa Instituição, nossa instigação foi a de tornar a experiência mais sadia possível, frente à complexidade do momento. $\mathrm{O}$ contexto da pandemia projetou a todos em uma condição de aulas remotas, encontros virtuais e tarefas digitais que tornaram a experiência do estágio algo inimaginável. Nosso desafio foi criar condições de execução, acompanhamento e avaliação a partir das experiências acumuladas, mas em uma realidade absolutamente desconhecida. Buscando enfrentar a verve de adoecimento que sobreveio, nos propusemos a pensar uma experiência saudável envolvendo professores e estudantes a fim de alcançar nosso principal objetivo neste momento de curso - vivenciar a prática pedagógica como experiência culminante da formação inicial de professores.

O Estágio Curricular nos Anos Iniciais do Ensino Fundamental é um dos momentos mais esperados do curso de Pedagogia, pois traz à baila o repertório curricular conhecido e apreendido, mobiliza as competências adquiridas e suscita aquelas que se precisa ainda alcançar, a fim de que um projeto de ação pedagógica, reflexivo e problematizador da própria docência, se constitua e aconteça. Por sua especificidade, pela natureza da prática e por sua extensão (são trezentas e sessenta horas, sendo trezentas no espaço escolar e sessenta na instituição formadora), fomos lançados em um estado de incerteza e intranquilidade frente à necessidade de validação do processo.

Os estudantes, com pouco ou nenhuma experiência docente nesse nível de ensino, começaram realizando entre vinte e cinco e trinta horas de observação no campo de estágio. Devido à singularidade produzida pela pandemia de COVID-19, fomos interpelados por medidas que autorizavam, em caráter excepcional, a substituição das aulas presenciais, em andamento, por aulas que utilizassem meios e tecnologias de informação e comunicação e, ainda, que pudessem ser adotadas atividades não presenciais para aulas práticas e estágios em 
todas as áreas. Essa mudança de contexto causou nossa principal apreensão - levando-nos, em cada encontro pedagógico com nossos estudantes, a estimular otimismo e paciência.

As medidas publicadas foram a Portaria $n^{\circ}$ 188, de 3 de fevereiro de 2020 (Emergência em Saúde Pública de Importância Nacional - ESPIN), a Portaria $n^{\circ} 343$, de 17 de março de 2020 (substituição das aulas presenciais por aulas em meios digitais), a Portaria $\mathrm{n}^{\circ} 345$, de 19 de março 2020 (alteração de prazo), a Portaria n 473, de 13 de maio de 2020 (alteração de prazo) e a Medida Provisória $n^{\circ}$ 934, de 01 de abril 2020 (normas excepcionais sobre o ano letivo da educação básica e do ensino superior) (BRASIL, 2020a, 2020b, 2020c, 2020d, 2020e). Tão logo a publicação das referidas medidas dispensou as instituições de ensino, em caráter excepcional, da obrigatoriedade de observância do número mínimo de dias de efetivo trabalho acadêmico, bem como de práticas presenciais, adequamos a organização do processo formador docente, ajustando o estágio curricular em sua totalidade ao modelo remoto e iniciamos uma experiência de acompanhamento e avaliação dentro de novos parâmetros.

\section{E-portfólio como meio de expressão e instrumento de análise de aprendizagem}

A opção pelo e-portfólio como instrumento de análise e de expressão de aprendizagem se deu por compreendemos a necessidade ampliar a autoria e a apropriação da própria aprendizagem e, por outro lado, do nosso processo de ensino, uma vez que o impedimento do exercício de prática docente no chão da escola afetou a proposta que havíamos programado com o grupo de estudantes, desde o ano anterior. Ao mesmo tempo, a escolha pelo e-portfólio possibilitou a ampliação do repertório de pesquisa, de planejamentos, das trocas discentes e docentes, de inventividade e de certa ousadia na expressão de seus resultados.

O portfólio é um álbum, dossiê ou documento com o registo individual de um processo, uma coleção de registros de habilidades, experiências e reflexões. Sua origem remonta a meados do século XVIII, à palavra italiana portafoglio - do portare, de portar, levar, carregar e, mais foglio, folha de papel, utilizado inicialmente nas Artes Visuais, designando as pastas de artistas da época que viajavam de uma cidade a outra mostrando seus esboços e criações (ALVARENGA, 2006).

Com base na elaboração de portfólios, Brito (2009) compreende que é possível ser criativo durante a construção de conhecimento, registrando a expressão de nosso percurso de aprendizagem. É um dispositivo por cuja construção processual nos permite apreciar, acompanhar e avaliar o próprio percurso de aprendizagem (e de ensino). Na mesma direção, Vieira (2002) observa que se trata de um aparato para arquivar de maneira organizada tudo 
aquilo com o que se trabalhou, tudo o que se desenvolveu por algum período em uma instituição - e isso inclui planos, esboços, rascunhos, textos de aulas, atividades, trabalhos, apostilas, exercícios de pesquisa. Para Hernandez (2000), o portfólio é um continente de diferentes tipos de documentos, anotações pessoais experiências de aula, trabalhos pontuais, controles de aprendizagem, conexões com os temas (fora ou dentro da instituição educacional), com representações gráficas de tudo aquilo que representa indícios ou evidências de um processo de conhecimento e suas estratégias correlatas para aprender e ensinar, com a disposição de quem o elabora, para continuar aprendendo.

Estas ideias impulsionaram nossa opção em fazer daquele momento não apenas um protocolo e uma avaliação, mas uma experiência coletiva de aprendizagem significativa que produzisse efeitos mais aproximados ao cotidiano da prática.

Conforme Vieira (2002), o portfólio em educação se articula à necessidade de consolidar e aprofundar o conhecimento sobre a relação ensino e aprendizagem, pois permite uma compreensão maior do que foi ensinado, como foi ensinado, o que foi aprendido e como foi aprendido. Quando se procurava encontrar soluções para que a educação acompanhasse as rápidas mudanças do mundo pandêmico, nos pareceu um instrumento razoável.

\section{Organização do e-portfólio no estágio supervisionado em tempos de pandemia}

Após a opção pelo portfólio, nossa próxima provocação foi a da escolha de uma ferramenta digital que permitisse o armazenamento e o compartilhamento. Entre aquelas encontradas no mercado, nos detivemos no blog, no site e no padlet, ferramentas colaborativas e disponíveis no modo gratuito.

A opção pela ferramenta digital para produzir, armazenar e compartilhar o portfólio em e-portfólio se baseou na familiaridade de nossos estudantes com a ferramenta padlet. Diante dessa escolha, nossa próxima tarefa consistiu em formalizar o registro do estágio em sete etapas, a partir da seguinte estrutura: período de observação: relato em até três laudas as observações realizadas antes do início da quarentena; atividades diversificadas: planejamento de uma atividade referente à pandemia do COVID-19, destacando-se a caracterização da faixa-etária de acordo com a turma de realização do estágio, e discussão sobre práticas inovadoras a partir de vídeos de situações de aula disponibilizados no ambiente moodle da disciplina; planejamento: projeto para um mês de regência, elaborado de acordo com as orientações institucionais para o estágio (o planejamento foi referente quatro semanas, cinco dias por semana com quatro horas de aula em cada dia); fórum dos estágios: sessão coletiva, utilizando 
ferramenta de reunião virtual, para descrição, pelos estagiários, daquela que consideravam a melhor atividade, justificando a sua escolha; regência: seis lives e/ou seis podcasts correspondentes a cada semana de aula, com disponibilização do enlace no padlet; reflexão final: realizar uma reflexão final sobre a experiência de estágio, destacando os desafios e as potencialidades dentro do contexto pandêmico; publicação final do e-portfólio: organização dos registros, narrativas, materiais, objetos de ensino, memória e reflexão sobre o percurso.

Ou seja, nos e-portfólios foram se materializando e expressando os entendimentos e as compreensões realizadas pelos estudantes sobre o processo vivido, na medida em que sentidos foram sendo atribuídos às aprendizagens realizadas na experiência singular e excepcional do estágio. Foram produzidos em torno de trinta e-portfólios, com os mais diferentes cenários, com as mais diversas cores, gravações, imagens e cenas. A sistematização do material foi caracterizando o modo como cada um dos estagiários se apropriou, reconheceu e significou esse momento de aprendizagem. Entre as sistematizações, fazemos alguns destaques:

Para mim as práticas no estágio da educação infantil foram importantes para construir a escrita do relatório do estágio. No entanto, na construção do e-portfolio, a ausência da prática com os alunos despertou um sentimento que estava faltando alguma coisa, mas sobraram momentos de reflexões e planejamentos e, logo, este sentimento foi se dissipando. Por isso, acredito que a qualidade na construção on-line foi a cereja que faltava em minha formação. Os alunos mudaram, logo a educação precisa atualizarse e repensar a prática educativa. Não me faltaram textos, vídeos, observações de aulas e ensino ao longo da graduação para desenvolver muitas reflexões e conteúdos. (ESTUDANTE A).

A Estudante B, relata o quão positivo foi traduzir suas experiências:

Acredito que fazer um e-portfólio foi uma maneira diferente de contar a trajetória do estágio, vejo como positiva a experiência. No e-portfólio trouxemos todas as propostas que fomos fazendo durante o semestre, uma apresentação de quem somos e de como foi nossa trajetória.

Para outra estudante, reconhece a facilidade de acesso e de publicização de sua aprendizagem:

\footnotetext{
Eu acho que o portfólio permite que a gente mostre toda a trajetória e trabalho feito durante o estágio de uma forma mais "simples" e mais visível. Os outros alunos buscariam mais facilmente ideias e modelos do estágio através do portfólio do que no relatório que, na maioria das vezes, é gigantesco. Além, também, do meio ambiente e cotas de impressão. O portfólio 'dá mais gosto' de ver e expor todo trabalho feito e dedicado. (ESTUDANTE C).
}

Também foi notória a repercussão e os prolongamentos de efeito do e-portfólio no contexto familiar dos estudantes, uma vez que essa ferramenta digital permitiu não apenas que familiares e amigos tivessem acesso ao material e fizessem alguma apreciação, mas permitiu que alguns deles também participassem das atividades e cenas. Além de se tornar um 
documento permanente de elaboração, reelaboração, do percurso, o dispositivo possibilitou a apropriação efetiva, por parte dos estudantes, da sua própria aprendizagem.

Mesmo com certas regras a serem seguidas, os estudantes assumiram a autoria da feitura individual e coletiva, acompanhando nossas apreciações, edições, controlando alterações e inserções, experimentando formatos gráficos tanto do e-portfólio quanto dos objetos, ousando na aparência e no modo de apresentação visual. A experiência pela via da conectividade digital permitiu a inter-relação conosco, professores supervisores do estágio, assim como a muitos dos professores titulares das turmas observadas (a quem se destinavam as atividades planejadas). Ao longo de todo o semestre permanecemos mantendo contato, trocando ideias, e com acesso ao e-portfólio em construção, discutindo a concepção e a elaboração de atividades para os alunos das turmas observadas. Nossa impressão é a de que a excepcionalidade da situação permitiu que todos nos envolvêssemos no processo de maneira ativa e propositiva, com um saldo positivo em nossa formação, como revela uma estudante:

Chego ao final desse semestre me sentindo vitoriosa, aprendi muitas lições diferentes e valiosas. Talvez algumas pessoas pensem que por ser a distância não aprendemos, que foi mais fácil, mas não foi. Saímos desse estágio fortalecidos, preparados para outras formas de ensino não tão tradicionais e, acima de tudo, com uma visão cada vez mais humana da educação. (ESTUDANTE D).

A experiência com os e-portfólios contribuiu com a abertura para uma compreensão (para nós, inédita) da potência pedagógica da ferramenta como um instrumento em processo, uma ferramenta que articulou todos os sujeitos no exercício do juízo, da apreciação e da avaliação. Para nós, professores supervisores, o dispositivo apareceu como instrumento metodológico com possibilidades muito além da verificação de aprendizagem, tendo impulsionado uma densa reflexão acerca dos valores, critérios e princípios que regulam a intencionalidade docente naquele momento da formação pedagógica de estudantes do curso de Pedagogia. Tomá-lo como objeto de análise, mediante nossas experiências no presente contexto, permite ampliar a possibilidade e a potencialidade de transformarmos nosso ofício, ou seja, a dinamicidade desse processo é desafiadora e inquietadora, e a experiência dos $e$ portfólios contribuiu para essa nossa revisão.

\section{Concluindo}

A proposição dos e-portfólios mobilizou uma nova tomada de consciência sobre as implicações que temos na formação de pedagogos (com ressonância na nossa atuação nas demais licenciaturas). Nos fez refletir sobre nossa experiência permanente de aprender enquanto ensinamos e do quão efetivamente interagimos (entre nós e com os estudantes), 
manejando efeitos da implicação de uns sobre os outros, acompanhando a prática de cada um e todos, promovendo uma avaliação permanente, continuada e formativa, ombro a ombro com os futuros professores. São modos de ensinar e de aprender que colocam em questão as nossas convicções e nos deslocam da habitual zona de conforto do dia-a-dia. Na expressão de Rancière (2004), escapamos do embrutecimento, aprendemos e ensinamos mesmo diante de um contexto completamente adverso e inusitado, carregado de muitas perdas, de isolamento, de (sobre)vivência e frustrações.

Retomando nossas ponderações iniciais, reiteramos a ideia de que a avaliação pode ser considerada um procedimento corriqueiro, mas ela é um expediente de alta complexidade e relevância para desenhar os rumos do processo de formação coletivo e individual, ao mesmo tempo que ele acontece. Neste trabalho, procuramos ampliar a ideia de avaliação restrita à aprendizagem de conteúdos e habilidades articuladas ao conjunto de saberes necessários ao ingresso em uma profissão. Ao colocar em análise uma das nossas experiências avaliativas, entendemos que é o próprio fundamento da avaliação que colocamos em questão, e não apenas a particularidade de uma prática mais ou menos bem-sucedida.

Fomos interpelados por um estado de realidade desconhecido, para o qual ninguém estava preparado ou sabia como lidar. Tivemos que inventar estratégias de manejo do cotidiano permanentemente. Ao contrário das experiências regulares, quando seguimos planos e protocolos já experimentados e praticados inúmeras vezes, e sobre os quais temos a prerrogativa de condução, durante o período da pandemia abraçamos a diversidade e a heterogeneidade do grupo de estudantes, e experimentamos, como um coletivo, enfrentar os limites dessa condição. Mais do que centrar a avaliação em expedientes de mensuração da aprendizagem objetiva, tratou-se de ampliar o entendimento de ação pedagógica e, professores e estagiários, utilizamos juntos os conhecimentos que tínhamos como ponto de partida para interferir na realidade e enfrentar aquilo que se caracterizava como um problema, na construção coletiva de um projeto para o estágio supervisionado a partir da leitura e interpretação da realidade que se abateu sobre nós.

\section{Referências}

ALVARENGA, G. M. et al. Portfólio: conceitos básicos e indicações para utilização. Estudos em Avaliação Educacional, São Paulo, v. 17, n. 33, p. 137-145, jan./abr. 2006.

BARKLEY, E. F.; MAJOR, C. H. Técnicas para avaliação da aprendizagem: um manual para professores universitários. Curitiba: PUCPRESS, 2020. 
BENÍTEZ, R.; AGUILAR, S.; SÁNCHEZ, L. Una experiencia para atender a la diversidad en la universidad. Márgenes, Málaga, 0 (0), p. 76-96, 2019. Disponível em: http://dx.doi.org/10.24310/mgnmar.v0i0.6230 Acesso em 2/07/2020.

BRASIL. Lei de Diretrizes e Bases da Educação Nacional. Lei número 9394, de 20 de dezembro de 1996. Brasília: MEC, 1996. Disponível em:

http://www.planalto.gov.br/ccivil_03/Leis/L9394.htm Acesso em: 2/07/2020.

BRASIL. Plano Nacional de Educação. Brasília: MEC, 2004. Disponível em: http://www.planalto.gov.br/ccivil_03/_Ato2011-2014/2014/Lei/L13005.htm Acesso em: 2/07/2020.

BRASIL. Base Nacional Comum Curricular. Brasília: MEC, 2019. Disponível em: $\mathrm{http} / / /$ basenacionalcomum.mec.gov.br/images/BNCC_EI_EF_110518_versaofinal_site.pdf Acesso em: 2/07/2020.

BRASIL. Medida Provisória n 934, de 01 de abril 2020. Brasília: Câmara dos Deputados, 2020a. Disponível em: https://www.in.gov.br/en/web/dou/-/medida-provisoria-n-934-de-1-deabril-de-2020-250710591 Acesso em: 2/07/2020.

BRASIL. Portaria $\mathrm{n}^{\circ}$ 188, de 3 de fevereiro de 2020. Brasília: Ministério da Saúde, 2020b. Disponível em: https://www.in.gov.br/en/web/dou/-/portaria-n-188-de-3-de-fevereiro-de2020-241408388 Acesso em: 2/07/2020.

BRASIL. Portaria n ${ }^{\circ}$ 345, de 19 de março 2020. Brasília: MEC, 2020c. Disponível em: https://www.in.gov.br/en/web/dou/-/portaria-n-345-de-19-de-marco-de-2020-248881422 Acesso em 02 de julho de 2020.

BRASIL. Portaria ${ }^{\circ}$ 473, de 13 de maio de 2020. Brasília: MEC, 2020d. Disponível em: https://www.in.gov.br/en/web/dou/-/portaria-n-473-de-12-de-maio-de-2020-256531507 Acesso em 02 de julho de 2020.

BRASIL. PORTARIA Nº 343, DE 17 DE MARÇO DE 2020. Brasília: MEC, 2020e. Disponível em: https://www.in.gov.br/en/web/dou/-/portaria-n-343-de-17-de-marco-de-2020248564376 Acesso em 02 de julho de 2020.

BRITO, C. R. S. Estudo de caso do portfólio às competências. Dissertação (Mestrado em Estudos Culturais, Didácticos, Linguísticos e Literários). Covilhã: Universidade da Beira Interior, 2009.

CARVALHO, A. M. P.; GIL-PEREZ, D. Formação de professores de Ciências: tendências e inovações. São Paulo: Cortez, 2006.

CARROLL, L. Alice do outro lado do espelho. Lisboa: Europa-América, 2010.

FOUCAULT, M. Vigiar e punir: nascimento da prisão. 31. ed. Petrópolis: Vozes, 2006.

GARCIA, J. Avaliação e aprendizagem na educação superior. Estudos sobre Avaliação Educacional, São Paulo, v. 20, n. 43, maio/ago. 2009. Disponível em: http://www.fcc.org.br/pesquisa/publicacoes/eae/arquivos/1489/1489.pdf Acesso em: 2/07/ 2020. 
GIL, A. C. Didática do ensino superior. São Paulo: Atlas, 2008.

GRÉGOIRE, J. et al. Avaliando as aprendizagens: os aportes da psicologia cognitiva. Porto Alegre, ARTMED, 2000.

GRILO, M.; GESSINGER, R. (org.). Por que falar ainda em avaliação? Porto Alegre: Edipucrs, 2010.

HERNÁNDEZ, F. Cultura visual: mudança educativa e projeto de trabalho. Porto Alegre: Artmed, 2000.

HOFFMANN, J. Avaliar: respeitar primeiro, educar depois. Porto Alegre: Mediação, 2008.

INEP. Sinopse estatística da educação Superior 2018. Brasília: INEP, 2019. Disponível em: http://download.inep.gov.br/informacoes_estatisticas/sinopses_estatisticas/sinopses_educacao _superior/sinopse_educacao_superior_2018.zip. Acesso em: 2 jul. 2020.

KANT, I. Sobre Pedagogia. Piracicaba: UNIMEP, 1996.

LUCKESI, C. Avaliação da aprendizagem escolar. 22. ed. São Paulo: Cortez, 2017.

PERRENOUD, P. Avaliação da excelência à regularização das aprendizagens: entre duas lógicas. Porto Alegre: Artmed, 1999.

RANCIÈRE, J. O mestre ignorante: cinco lições sobre a emancipação intelectual. 2. ed. Belo Horizonte: Autêntica, 2004.

SACRISTÁN, J.; GÓMEZ, A. P. Compreender e transformar o ensino. Porto Alegre: ARTMED, 1998.

SILVA, J. F. Avaliação formativa: pressupostos teóricos e práticos. Porto Alegre: Mediação, 2019.

VASCONCELLOS, C. S. Avaliação da aprendizagem: práticas de mudança. São Paulo: Libertad, 2013.

VIEIRA, V. M. O. Portfólio: uma proposta de avaliação como reconstrução do processo de aprendizagem. Revista Psicologia Escolar e Educacional, São Paulo, v. 6, n. 2, p. 149-153, junho/dezembro 2002.

ZABALZA, M. O ensino universitário: seu cenário e protagonistas. Porto Alegre: ARTMED, 2013.

ZAINKO, M. A. S. Educação superior, democracia e desenvolvimento humano sustentável. In: ZAINKO, M. A. S.; GISI, M. L. (org.). Políticas e gestão da educação superior. Curitiba: Champagnat, 2003. p. 45-60. 